\title{
Clinical characteristics and prognosis of acute myocardial infarction in young smokers and non-smokers ( $\leq 45$ years): a systematic review and meta-analysis
}

\author{
Yuqi Liu ${ }^{1, *}$, Tianwen Han ${ }^{1, *}$, Ming Gao ${ }^{2, *}$, Jinwen Wang ${ }^{3}$, Fang Liu ${ }^{3}$, Shanshan Zhou ${ }^{1}$ \\ and Yundai Chen ${ }^{1}$ \\ ${ }^{1}$ Department of Cardiology, PLA General Hospital, Beijing 100853, China \\ ${ }^{2}$ ICU of The First Phase Beijing Tsinghua Changgeng Hospital, Beijing 100044, China \\ ${ }^{3}$ Department of Cardiology of Anzhen Hospital, Beijing 100029, China \\ *These authors contributed equally to this work
}

Correspondence to: Yundai Chen, email: cyundai@vip.163.com

Keywords: young, AMI, smoking, prognosis, meta-analysis

Received: June 04, $2017 \quad$ Accepted: September 04, $2017 \quad$ Published: September 20, 2017

Copyright: Liu et al. This is an open-access article distributed under the terms of the Creative Commons Attribution License 3.0 (CC BY 3.0 ), which permits unrestricted use, distribution, and reproduction in any medium, provided the original author and source are credited.

\section{ABSTRACT}

The effect of smoking on the prognosis of young patients with acute myocardial infarction ( $A M I$ ) is inconclusive. We enrolled 2188 young AMI patients ( $\leq 45$ years) from the cardiac center of the Chinese PLA General Hospital and Anzhen Hospital and analyzed their clinical characteristics and prognosis. We also searched the PubMed, EMBASE, and Cochrane Central Register of Controlled Trials electronic databases for January 2001 to March 2017 and considered for inclusion in a meta-analysis those clinical trials that compared prognoses of young smokers and non-smokers with AMI. The proportion of males and alcohol users was higher in young AMI smokers than in non-smokers; the proportion of hypertension was slightly lower. There was no difference in medical treatment between smokers and non-smokers. No differences were evident between smokers and non-smokers regarding in-hospital cardiac events and major adverse cardiovascular events on follow-up, including incidence of stroke. For young AMI patients, smoking did not lead to poorer prognosisin comparison with not smoking. This "smoker's paradox" needs to be confirmed by more randomized controlled multicenter prospective clinical trials.

\section{INTRODUCTION}

Worldwide, the incidence of coronary heart disease (CHD) is increasing. One Chinese report on cardiovascular disease in 2014 estimated that cardiovascular disease globally affected about 290 million people. Accordingly, the burden of cardiovascular disease is rising and has become a major public health problem [1]. With changes in lifestyle, dietary structure, and stress, the age of CHD has been lowered. Acute myocardial infarction (AMI) is a disease with high mortality that presents a serious threat to human life and health. In recent years, the incidence of MI in young people has shown an upward trend. Many epidemiological studies have found that common risk factors of CHD include smoking, male sex, family history of CHD and cerebrovascular disease, dyslipidemia, obesity, hypertension, and diabetes [2-4]. According to the INTERHEART study [5], the risk of smokers developing CHD after quitting smoking shows an annual decrease.

Loukianos et al. determined that persistence of smoking, left ventricular ejection fraction, and reperfusion therapy were independent predictors of major adverse cardiovascular events (MACEs) after adjustment for conventional risk factors [6]. However, other studies arrived at the opposite conclusion: AMI patients who were smokers had survival advantages compared with those who were non-smokers [7-9]. Kang-Yin et al. found that AMI patients who were smokers had lower rates of in-hospital cardiac death and overall mortality than nonsmokers [10]. Given the debatable smoking among young patients with AMI in the present study we examined the effect of smoking in young AMI patients on the in- 
hospital and out of hospital prognosis after the event; we also undertook a systematic review and meta-analysis and compared our findings with those of previous studies.

\section{RESULTS}

\section{Clinical characteristics of young AMI patients}

We evaluated the interaction of smoking with other factors, including gender, alcohol consumption, hypertension, diabetes, hyperlipidemia and family history of CHD. The results showed that interactions with other factors were eliminated (see Supplementary Table 1). The clinical characteristics indicated a higher proportion of males and alcohol consumers among young AMI smokers than in young non-smokers (Table $1 ; P<0.05$ ). The proportion of hypertension was slightly lower among smokers than in non-smokers. There were no differences in medical treatment (including aspirin, clopidogrel, statin, ticagrelor, ACEIs (angiotensin converting enzyme inhibitors) or ARBs (angiotensin II-receptor-blockers), $\beta$-blockers, CCBs (calcium channel blockers), and nitrate) between smokers and non-smokers (Table 2; $P>0.05$ ). There was likewise no difference in in-hospital cardiac events and MACEs at follow-up between smokers and non-smokers (Table 3).

The clinical baseline data showed that young AMI patients with in-hospital cardiac events presented a higher heart rate and creatinine kinase (CK), troponin $\mathrm{T}$ and glucose levels, and lower red cell count (RCC), platelet count, and ejection fraction than patients without cardiac events (Table $4 ; P>0.05$ ). The proportion of non-
ST-elevation MI was higher in patients with in-hospital cardiac events than in those without such events.

With respect to in-hospital cardiac events, alcohol use was lower in patients with MACEs at follow-up than in those without MACEs. At follow-up, the RCC was lower and the CK level and red blood cell distribution width higher in patients with MACEs than in those without MACEs.

\section{Meta-analysis for prognoses of smokers and non- smokers}

\section{Prognosis in hospital}

Heterogeneity analysis showed $I^{2} 82.1 \%$ and $P$ 0.018 , and the fixed model was replaced by a randomized model. In two clinical trials, the incidence of in-hospital cardiac events showed no difference between young smokers and non-smokers; the proportion of major cardiac events was $3.4 \%(87 / 2496)$ in smokers compared with 5.7\% (52/910) in non-smokers (OR, 0.48; 95\% CI, $0.14-1.61 ; P=0.235$; Figure 1$)$. The $P$ value of Begg's Test was 0.317 .

\section{Prognosis during follow-up}

In five clinical trials, the heterogeneity analysis showed $I^{2} 76.2 \%$ and $P 0.002$, and the fixed model was replaced by a randomized model. During follow-up there was no difference in the incidence of MACEs between young smokers and non-smokers; the proportion of all MACEs was $9.8 \%(270 / 2755)$ in smokers compared with

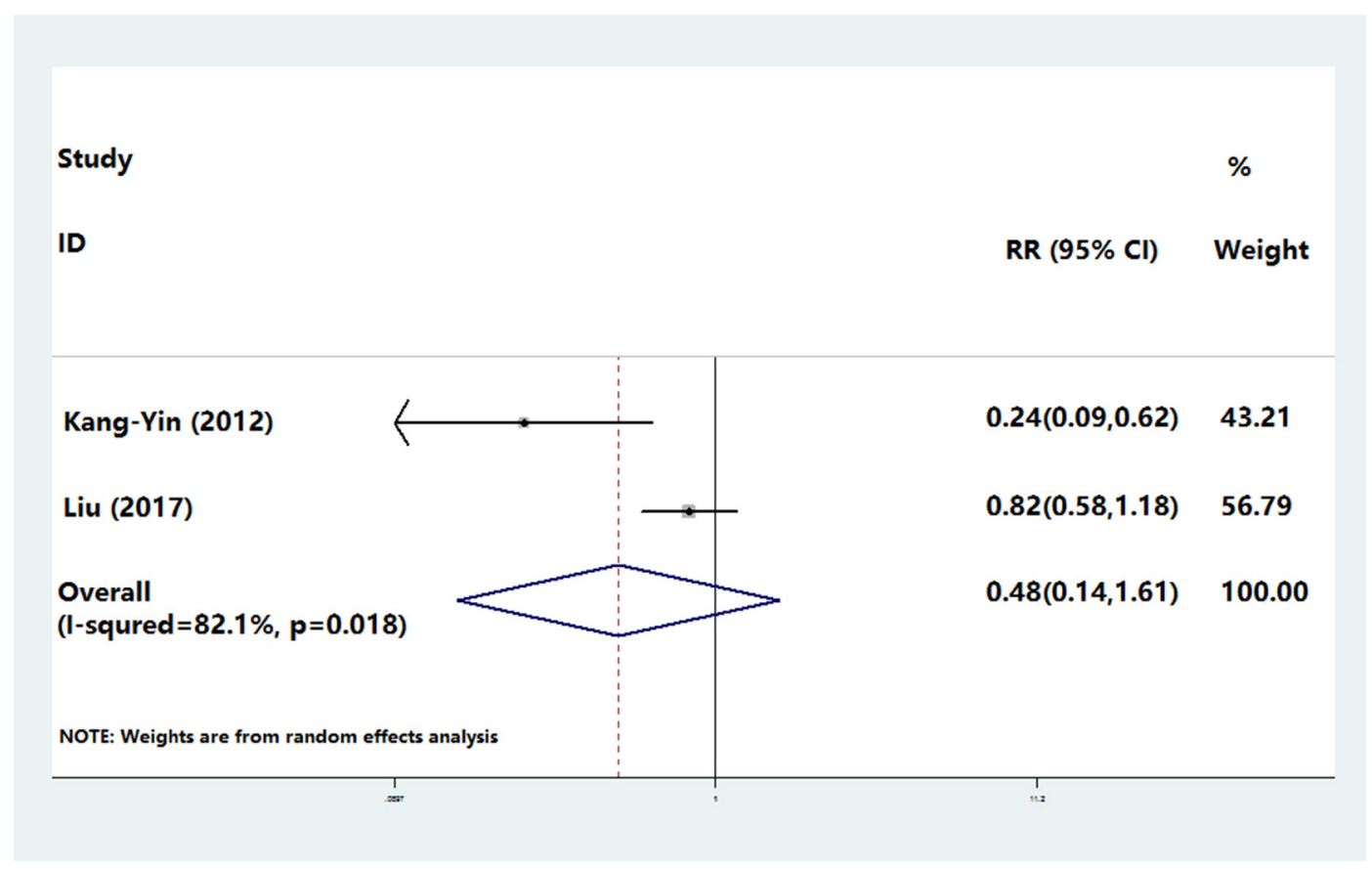

Figure 1: The incidence of in-hospital cardiac events compared between young smokers and non-smokers. $3.4 \%$ (87/2496) in smokers compared with 5.7\% (52/910) in non-smokers (OR, 0.48; 95\% CI, 0.14-1.61; P 0.235). 
Table 1: Clinical characteristics of young patients with AMI

\begin{tabular}{cccc}
\hline Variables & \multicolumn{2}{c}{ Groups } & P-value \\
\cline { 2 - 3 } & $\begin{array}{c}\text { Smoker } \\
(\boldsymbol{n}=\mathbf{1 5 0 6})\end{array}$ & $\begin{array}{c}\text { Non-smoker } \\
(\boldsymbol{n}=\mathbf{6 8 2})\end{array}$ & \\
\hline Deographic and clinical & & & \\
Age (yrs) & $39.8 \pm 4.7$ & $39.9 \pm 4.6$ & NS \\
Heart rate (beats/min) & $74.2 \pm 12.8$ & $73.5 \pm 13.2$ & NS \\
SBP (mm Hg) & $120.8 \pm 16.2$ & $120.6 \pm 17.0$ & NS \\
DBP (mm Hg) & $75.7 \pm 11.8$ & $76.4 \pm 12.7$ & NS \\
Body mass index (kg/m2) & $28.2 \pm 3.2$ & $28.0 \pm 3.2$ & NS \\
Male (\%) & $1493(99.1)$ & $584(85.6)$ & 0.000 \\
Alcohol use (\%) & $561(37.2)$ & $85(12.4)$ & 0.000 \\
Hypertension (\%) & $573(38.0)$ & $302(44.2)$ & 0.006 \\
Diabetes mellitus (\%) & $300(19.9)$ & $118(17.3)$ & NS \\
Hyperlipidemia (\%) & $475(31.5)$ & $208(30.4)$ & NS \\
Family historyof CAD (\%) & $183(12.1)$ & $72(10.5)$ & NS \\
Prior MI (\%) & $63(4.1)$ & $30(4.3)$ & NS \\
\hline
\end{tabular}

$9.0 \%(103 / 1140)$ in non-smokers $(\mathrm{OR}, 1.45 ; 95 \% \mathrm{CI}$, $0.90-2.32 ; P=0.123$; Figure 2) with no heterogeneity across the trials (Figure 2 and Supplementary Table 4). The sensitivity analysis showed that small-sample trials ( $<500$ subjects) showed more cardiac events in the non-smoker group $(P=0.001$, Supplementary Table 4$)$; however this difference disappeared in larger trials $(P=0.434$, Supplementary Table 4$)$.

\section{DISCUSSION}

It is accepted by most researchers that smoking is one of the major risk factors of CHD. Smoking may contribute to the occurrence and development of CHD by affecting lipid metabolism, inflammatory reactions, and vascular endothelial dysfunction [14-16]. It is also evident that there is a significant correlation between

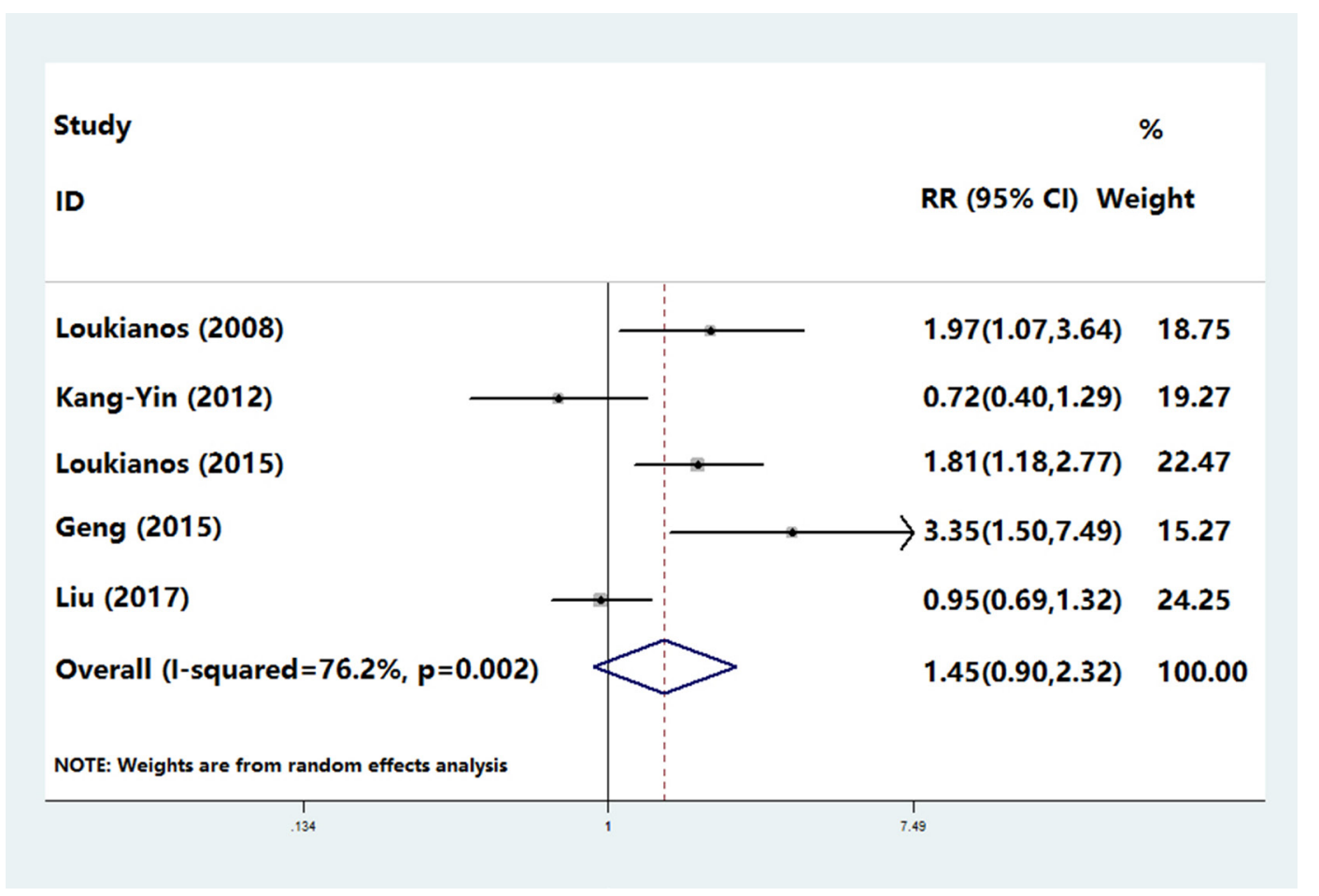

Figure 2: The incidence of MACEs between young smokers and non-smokers. 9.8\% (270/2755) in smokers compared with $9.0 \%(103 / 1140)$ in non-smokers (OR, 1.45; 95\% CI, 0.90-2.32; $P$ 0.123) 
Table 2: Medical therapy according to the smoker

\begin{tabular}{lccc}
\hline Variables & $\begin{array}{c}\text { Smoker } \\
(\boldsymbol{n}=\mathbf{1 5 0 6})\end{array}$ & $\begin{array}{c}\text { Non-smoker } \\
(\boldsymbol{n}=\mathbf{6 8 2})\end{array}$ & $\boldsymbol{P}$-value \\
\hline Aspirin & $1427(94.7)$ & $653(95.7)$ & NS \\
Clopidogrel & $1373(91.1)$ & $630(92.3)$ & NS \\
Statin & $1189(78.9)$ & $571(83.7)$ & NS \\
Ticagrelor & $35(2.3)$ & $23(3.3)$ & NS \\
ACEI/ARB & $627(41.6)$ & $297(43.5)$ & NS \\
ß blocker & $1163(77.2)$ & $527(77.2)$ & NS \\
CCB & $150(9.9)$ & $74(10.8)$ & NS \\
Nitrate & $988(65.6)$ & $452(66.2)$ & NS \\
\hline
\end{tabular}

ACEI: angiotension converting enzyme inhibitors; ARB: angiotensin II receptor blockers; CCB: calcium channel blockers.

Table 3: Outcomes in hospital and out hospital according to the smoker

\begin{tabular}{lccc}
\hline Variables & $\begin{array}{c}\text { Smoker } \\
(\boldsymbol{n}=\mathbf{1 5 0 6})\end{array}$ & $\begin{array}{c}\text { Non-smoker } \\
(\boldsymbol{n}=\mathbf{6 8 2})\end{array}$ & $\boldsymbol{P}$-value \\
\hline In hospital outcome & & & NS \\
death (\%) & $19(1.2)$ & $16(2.3)$ & \\
complications & & $20(2.9)$ & NS \\
$\quad$ Cardiogenic shock (\%) & $26(1.7)$ & $9(1.3)$ & NS \\
Major bleeding (\%) & $10(0.6)$ & 0 & NS \\
AVB (\%) & $5(0.3)$ & $31(4.5)$ & NS \\
VT or VF (\%) & $57(3.7)$ & $10(1.4)$ & NS \\
Thrombosis (\%) & $11(0.7)$ & $51(7.5)$ & NS \\
CHF (\%) & $98(6.5)$ & $44(6.4)$ & \\
Total events (\%) & $79(5.2)$ & 666 & NS \\
Out-hospital outcome & 1487 & $49(7.3)$ & NS \\
MACE (\%) & $104(6.9)$ & $1(0.1)$ & NS \\
death (\%) & $2(0.1)$ & $36(5.4)$ & NS \\
MI (\%) & $58(3.9)$ & $31(4.6)$ & NS \\
Re-PCI (\%) & $55(3.6)$ & 0 & NS \\
Re-CABG (\%) & $5(0.3)$ & $31(4.6)$ & \\
stroke (\%) & $57(3.8)$ & & \\
\hline
\end{tabular}

AKI: acute kidney injury; AVB: atrioventricular block; VT: ventricular tachyarrhythmia; VF: ventricular fibrillation.

cigarette smoking and the prognosis of patients with CHD $[17,18]$. However, early studies found greater survival among smokers with AMI in comparison with nonsmokers; this is termed the "smoker's paradox." Some researchers believe that this phenomenon may be related to non-smokers being older and having poorer prognosis. Thus, it is necessary to determine the effects of smoking on in-hospital and out-of-hospital prognosis in young AMI patients.

Recently, Kang-Yin et al. found that overall mortality was lower in young smokers with AMI, implying that smoking may have been a protective factor for MI. In the present study, clinical data analysis from our center showed no difference in follow-up between smokers and non-smokers with respect to in-hospital cardiac events and MACEs; one exception was that the incidence of stroke in smokers was lower than in non-smokers. The clinical baseline showed a higher proportion of males and alcohol users and a lower proportion of hypertension among smokers than among non-smokers. There was no difference in medicinal use (aspirin, clopidogrel, statin, ticagrelor, ACEIs/ARBs, $\beta$-blockers, CCBs, and nitrate) between the two groups. The meta-analysis found no difference between young smokers and non-smokers with respect to total in-hospital cardiac events. There was likewise no difference between the two groups for total MACEs during follow-up. On further analysis conducted according to the sample size (Supplementary Table 4), 
Table 4: Clinical characteristics of young patients with AMI

\begin{tabular}{|c|c|c|c|c|c|c|}
\hline \multirow[t]{2}{*}{ Variables } & \multicolumn{2}{|l|}{ Groups } & \multirow[t]{2}{*}{$P$-value } & \multicolumn{2}{|l|}{ Groups } & \multirow[t]{2}{*}{$P$-value } \\
\hline & $\begin{array}{l}\text { Non-events in hospital } \\
(n=2065)\end{array}$ & $\begin{array}{l}\text { Events in hospital } \\
(n=123)\end{array}$ & & $\begin{array}{l}\text { Non-events out of } \\
\text { hospital } \\
(n=2098)\end{array}$ & $\begin{array}{l}\text { Events out of } \\
\text { hospital } \\
(n=90)\end{array}$ & \\
\hline \multicolumn{7}{|l|}{ Deographic and clinical } \\
\hline Age (yrs) & $39.9 \pm 4.6$ & $39.4 \pm 4.9$ & NS & $39.8 \pm 4.7$ & $39.6 \pm 4.3$ & NS \\
\hline Heart rate (beats/min) & $73.4 \pm 12.7$ & $79.4 \pm 17.7$ & 0.000 & $73.7 \pm 13.0$ & $74.5 \pm 14.0$ & NS \\
\hline $\mathrm{SBP}(\mathrm{mm} \mathrm{Hg})$ & $120.8 \pm 16.3$ & $119.1 \pm 19.3$ & NS & $120.7 \pm 16.5$ & $120.5 \pm 16.2$ & NS \\
\hline DBP (mm Hg) & $75.9 \pm 11.9$ & $75.1 \pm 14.3$ & NS & $75.9 \pm 12.1$ & $76.7 \pm 12.5$ & NS \\
\hline BMI (kg/m2) & $28.1 \pm 3.2$ & $28.3 \pm 3.1$ & NS & $28.1 \pm 3.1$ & $28.2 \pm 3.6$ & NS \\
\hline Male (\%) & 1964(95.1) & 113(91.8) & NS & 1991(94.8) & $86(95.5)$ & NS \\
\hline Alcohol use (\%) & $615(29.7)$ & $31(25.2)$ & NS & $628(29.9)$ & $18(20.0)$ & 0.043 \\
\hline Smoke (\%) & $1427(69.1)$ & $79(64.2)$ & NS & $1449(69.0)$ & $57(63.3)$ & NS \\
\hline Hypertension (\%) & $816(39.5)$ & $59(47.9)$ & NS & $840(40.0)$ & $35(38.8)$ & NS \\
\hline Diabetes mellitus (\%) & $387(18.7)$ & $31(25.2)$ & NS & 401(19.1) & $17(18.8)$ & NS \\
\hline Hyperlipidemia (\%) & $667(32.3)$ & $39(31.7)$ & NS & $653(31.1)$ & $30(33.3)$ & NS \\
\hline Family historyof CAD (\%) & $244(11.8)$ & 11(8.9) & NS & $243(11.5)$ & $12(13.3)$ & NS \\
\hline Prior MI (\%) & $86(4.1)$ & $7(5.6)$ & NS & $91(4.3)$ & $2(2)$ & NS \\
\hline \multicolumn{7}{|l|}{ Biochemical } \\
\hline $\mathrm{TC}(\mathrm{mmol} / \mathrm{L})$ & $4.73 \pm 1.22$ & $4.58 \pm 1.07$ & NS & $4.73 \pm 1.22$ & $4.61 \pm 1.01$ & NS \\
\hline $\mathrm{TG}(\mathrm{mmol} / \mathrm{L})$ & $2.75 \pm 7.10$ & $2.01 \pm 1.29$ & NS & $2.75 \pm 7.09$ & $2.00 \pm 1.31$ & NS \\
\hline LDL-c (mmol/L) & $3.15 \pm 5.81$ & $2.80 \pm 0.88$ & NS & $3.15 \pm 5.81$ & $2.83 \pm 0.84$ & NS \\
\hline HDL-c (mmol/L) & $0.96 \pm 0.22$ & $0.98 \pm 0.26$ & NS & $0.96 \pm 0.22$ & $0.99 \pm 0.26$ & NS \\
\hline $\operatorname{Scr}(\mu \mathrm{mol} / \mathrm{L})$ & $80.28 \pm 38.51$ & $81.15 \pm 24.46$ & NS & $80.35 \pm 38.51$ & $79.85 \pm 23.54$ & NS \\
\hline BUN (mmol/L) & $7.35 \pm 4.82$ & $6.56 \pm 4.21$ & NS & $7.34 \pm 4.82$ & $6.85 \pm 4.34$ & NS \\
\hline $\operatorname{ALT}(\mathrm{U} / \mathrm{L})$ & $46.25 \pm 35.83$ & $56.76 \pm 41.31$ & NS & $46.35 \pm 35.88$ & $55.58 \pm 41.31$ & NS \\
\hline$\gamma-\mathrm{GT}(\mathrm{U} / \mathrm{L})$ & $51.88 \pm 48.94$ & $65.52 \pm 83.02$ & NS & $52.44 \pm 50.08$ & $66.40 \pm 89.18$ & NS \\
\hline $\mathrm{CK}(\mathrm{U} / \mathrm{L})$ & $842.38 \pm 1286.09$ & $1332.34 \pm 1708.09$ & 0.015 & $848.52 \pm 1293.33$ & $1229.67 \pm 1640.81$ & 0.049 \\
\hline CK-MB (ng/ml) & $79.84 \pm 181.77$ & $106.74 \pm 148.63$ & NS & $80.29 \pm 181.82$ & $98.99 \pm 147.31$ & NS \\
\hline $\mathrm{cTnT}(\mathrm{ng} / \mathrm{ml})$ & $2.17 \pm 2.04$ & $3.25 \pm 4.83$ & 0.048 & $2.20 \pm 2.21$ & $2.69 \pm 3.31$ & NS \\
\hline $\mathrm{BNP}(\mathrm{pg} / \mathrm{ml})$ & $481.87 \pm 2659.16$ & $1140.97 \pm 3404.97$ & NS & $483.85 \pm 2648.81$ & $1199.77 \pm 3624.89$ & NS \\
\hline Glucose $(\mathrm{mmol} / \mathrm{L})$ & $6.98 \pm 2.87$ & $8.08 \pm 4.90$ & 0.048 & $6.99 \pm 2.89$ & $7.94 \pm 4.86$ & NS \\
\hline Glycosylatedhemoglobin (\%) & $6.55 \pm 1.87$ & $6.10 \pm 1.32$ & NS & $6.48 \pm 1.82$ & $6.32 \pm 1.55$ & NS \\
\hline \multicolumn{7}{|l|}{ Hematologic } \\
\hline Hemoglobin $(\mathrm{g} / \mathrm{L})$ & $147.23 \pm 15.54$ & $143.74 \pm 16.65$ & NS & $147.22 \pm 15.57$ & $143.65 \pm 16.09$ & NS \\
\hline Red cell count $\left(10^{*} 12 / \mathrm{L}\right)$ & $5.83 \pm 2.04$ & $5.16 \pm 1.89$ & 0.003 & $5.83 \pm 2.04$ & $5.21 \pm 1.92$ & 0.008 \\
\hline White cell count $\left(10^{* 9 / \mathrm{L})}\right.$ & $10.42 \pm 3.55$ & $10.44 \pm 4.27$ & NS & $10.41 \pm 3.56$ & $10.53 \pm 4.25$ & NS \\
\hline $\operatorname{PLT}(10 * 9 / \mathrm{L})$ & $239.78 \pm 61.07$ & $210.60 \pm 46.11$ & 0.043 & $238.03 \pm 60.65$ & $215.60 \pm 50.72$ & NS \\
\hline RDW & $12.94 \pm 0.71$ & $13.25 \pm 0.95$ & NS & $12.94 \pm 0.70$ & $13.38 \pm 1.03$ & 0.034 \\
\hline \multicolumn{7}{|l|}{ Echocardiography } \\
\hline $\operatorname{LVDd}(\mathrm{mm})$ & $50.13 \pm 5.06$ & $50.15 \pm 5.62$ & NS & $50.14 \pm 5.13$ & $49.90 \pm 4.16$ & NS \\
\hline IVST (mm) & $10.20 \pm 1.58$ & $10.40 \pm 1.47$ & NS & $10.22 \pm 1.58$ & $10.20 \pm 1.29$ & NS \\
\hline $\mathrm{EF}(\%)$ & $57.70 \pm 8.52$ & $54.53 \pm 9.07$ & 0.000 & $57.45 \pm 8.54$ & $58.62 \pm 9.48$ & NS \\
\hline Diagnosis & & & 0.030 & & & NS \\
\hline NSTEMI & $1648(79.8)$ & $108(87.8)$ & & $1685(80.3)$ & $71(78.8)$ & \\
\hline STEMI & $417(20.1)$ & $15(12.1)$ & & 413(19.6) & $19(21.1)$ & \\
\hline
\end{tabular}

SBP: systolic blood pressure; DBP: diastolic blood pressure; HR: heart rate; BMI: Body Mass Index; NSTEMI: non-ST-segment myocardial infarction; STEMI: ST-segment elevation myocardial infarction; TC: total cholesterol; TG: triglyeride; LDL: low density lipoprotein cholesterol; HDL: high density lipoprotein cholesterol; Cr: creatinine; BUN: blood urea nitrogen; ALT: alanine aminotransferase; AST: Aspartate transaminase; CK: creatine kinase; CKMB: creatine kinase MB isoenzyme; cTnT: Cardiac Troponin T; NT-proBNP: N-terminal pro-B-type natriuretic peptide; HbA1c: hemoglobin A1c; PLT: platelet; RDW: red blood cell distribution width; LVDd: left ventricular end-diastolic dimension; IVST: interventricular septal thickness; EF: ejection fraction; NS: not significant. 
surprisingly we found that in the large-sample-trials the good prognosis shown by young smokers in the smaller trials disappeared.

The smoker's paradox is a very important issue, and has led clinicians and patients to make incorrect decisions. The mechanism of this phenomenon warrants further discussion and analysis. Some studies have suggested that it may be caused by the interaction of additional risk factors, such as age [19-21]. However, other studies have found that the phenomenon persisted even after correcting for these possible interference factors. Therefore, researchers have continued to explore the underlying mechanisms of the paradox. Recently it was demonstrated that smoking induces cytochrome P450 1A2 a hepatic enzyme involved in the metabolism of clopidogrel, and causes an increased clopidogrel response among smokers [22]. A subsequent study found that clopidogrel significantly reduced mortality in smokers but not in nonsmokers [23]. A more recent study evaluated data from the Clopidogrel in High-Risk Patients with Acute NonDisabling Cerebrovascular Events (CHANCE) trial [24] and determined that for secondary prevention, smoking status modified the effect of clopidogrel treatment on the outcome [25]. One study showed that clopidogrel likely had an enhanced effect in smokers versus nonsmokers because smoking is an inducer of clopidogrel metabolism, which results in greater degrees of platelet inhibition and less platelet aggregation with clopidogrel [26].

In conclusion, the effect of smoking on MI, especially in young AMI patients, remains questionable. According to our results it could be suggested that other CYP2Y12 receptor antagonists, for example ticagrelor, may be more suitable for young patients with AMI, especially nonsmokers, to bring more clinical benefits. In truth there remains a lack of research on the influence of smoking in the younger population $(\leq 45$ years) of AMI patients, as only five studies (including the present one from our center) met the criteria of our meta-analysis. In the future, therefore, more randomized controlled multicenter prospective clinical trials with larger sample sizes are needed to further investigate the role of smoking in the prognosis of young AMI patients. In addition, the potential mechanism of smoking in MI, the interaction between smoking and clopidogrel or other antiplatelet drugs, and details of the related mechanisms need to be confirmed by clinical and basic studies.

\section{MATERIALS AND METHODS}

\section{Subjects}

The study protocol has been approved by the Chinese PLA General Hospital and Anzhen Hospital review boards written informed consent and consent for publication has been obtained from all participants. The participants were 2188 patients diagnosed with AMI and $\leq 45$ years old who were enrolled from the cardiac center of the Chinese PLA General Hospital and Anzhen Hospital from January 2010 to December 2014. The diagnosis of AMI was made when ST elevation or depression or new left bundle-branch block with chest pain lasted more than 30 minutes and the myocardial enzyme level increased to more than twice the normal range [11]. The exclusion criteria included rheumatic heart disease, cardiomyopathy, congenital heart disease, severe congestive heart disease, malignant tumor, and use of the oral contraceptive pill or pregnancy.

\section{Clinical database collection and follow-up}

All clinical data were derived from hospitalized patients and included sex, age, smoking status, alcohol use, hypertension, hyperlipidemia, diabetes, and family history of coronary artery disease. Laboratory tests included total cholesterol, triglycerides, low-density lipoprotein cholesterol, high-density lipoprotein cholesterol, urea nitrogen, uric acid, creatine kinase $\mathrm{MB}$, troponin $\mathrm{T}$, serum creatinine, N-terminal pro-B-type natriuretic peptide, and routine blood tests. Echocardiographic parameters were assessed using transthoracic echocardiography with the Teichholz method prior to coronary angiography; they included left ventricular ejection fraction, thickness of the interventricular septum and left ventricular end-diastolic inner diameter.

In the hospital, the adverse events recorded included major bleeding, ventricular tachyarrhythmia (VT), ventricular fibrillation (VF), atrioventricular block (AVB), cardiogenic shock and thrombosis. Following hospital discharge, major adverse events were defined as cardiac death, AMI, percutaneous coronary intervention (PCI), coronary artery bypass grafting (CABG), and stroke. All subjects were regularly followed up for 1 year after their first hospitalization.

Complications during hospitalization included cardiogenic shock, AVB requiring temporary cardiac pacemaker insertion, VF or VT requiring anti-arrhythmic drugs or defibrillation and major bleeding. Major bleeding was defined as severe bleeding other than intracranial bleeding. MACEs during the follow-up period included cardiac death, emergency or elective repeat revascularization, AMI, and stroke. Cardiac death was defined as mortality resulting from cardiac disease.

\section{Literature search}

PubMed and Cochrane Central Register of Controlled Trials electronic databases and EMBASE were searched for the period January 2001 to March 2017. Observational or randomized trials that investigated prognoses for smokers and non-smokers among young AMI patients were identified using the following key words: "young," "AMI," and "smoking." All of the 
studies included in this meta-analysis compared the prognoses for smokers and non-smokers. All studies that met those criteria-regardless of the language or form of publication-were considered eligible for the metaanalysis.

\section{Selection criteria}

We selected only complete, published, nonconfounded trials. The inclusion criteria were as follows: (1) randomized controlled clinical trials or observational clinical trials; (2) comparison of prognoses in young smokers and non-smokers (aged $\leq 45$ years) with AMI. The exclusion criteria were as follows: (1) clinical outcomes in AMI patients whereby smokers and nonsmokers were not reported separately; (2) clinical outcomes of MACEs not reported; and (3) ongoing and duplicated reports or studies. The characteristics of the included studies, including the risk of bias for inclusion with the PEDro scale, are listed in Supplementary Table 2. The clinical characteristics of the clinical studies, if the data were provided in the articles, are listed in Supplementary Table 3.

\section{Data extraction}

Two authors (YQ Liu and TW Han) independently performed literature searches to identify all of the trials that met the inclusion criteria. The first authors and year of publication were recorded for each trial. A total of four clinical trials were considered to be potentially relevant (Figure 3).

\section{Statistical analysis}

We performed statistical analyses using SPSS (version 18.0), and Stata software (version 12.0). Continuous variables with normal distributions were expressed as mean \pm standard deviation and compared using one-way analysis of variance. Odds ratios (ORs) and $95 \%$ confidence intervals (95\% CIs) were employed as summary statistics. We calculated ORs for categorical variables using a random-effects model. Heterogeneity between studies was assessed with $I^{2}$ statistics $[9,10]$. Sensitivity analyses were conducted to assess differences by sample size $(<500$ versus $\geq 500)$ for outcomes. We examined potential publication bias and selection bias using

\section{1 citation retrieved from datab ase searches}

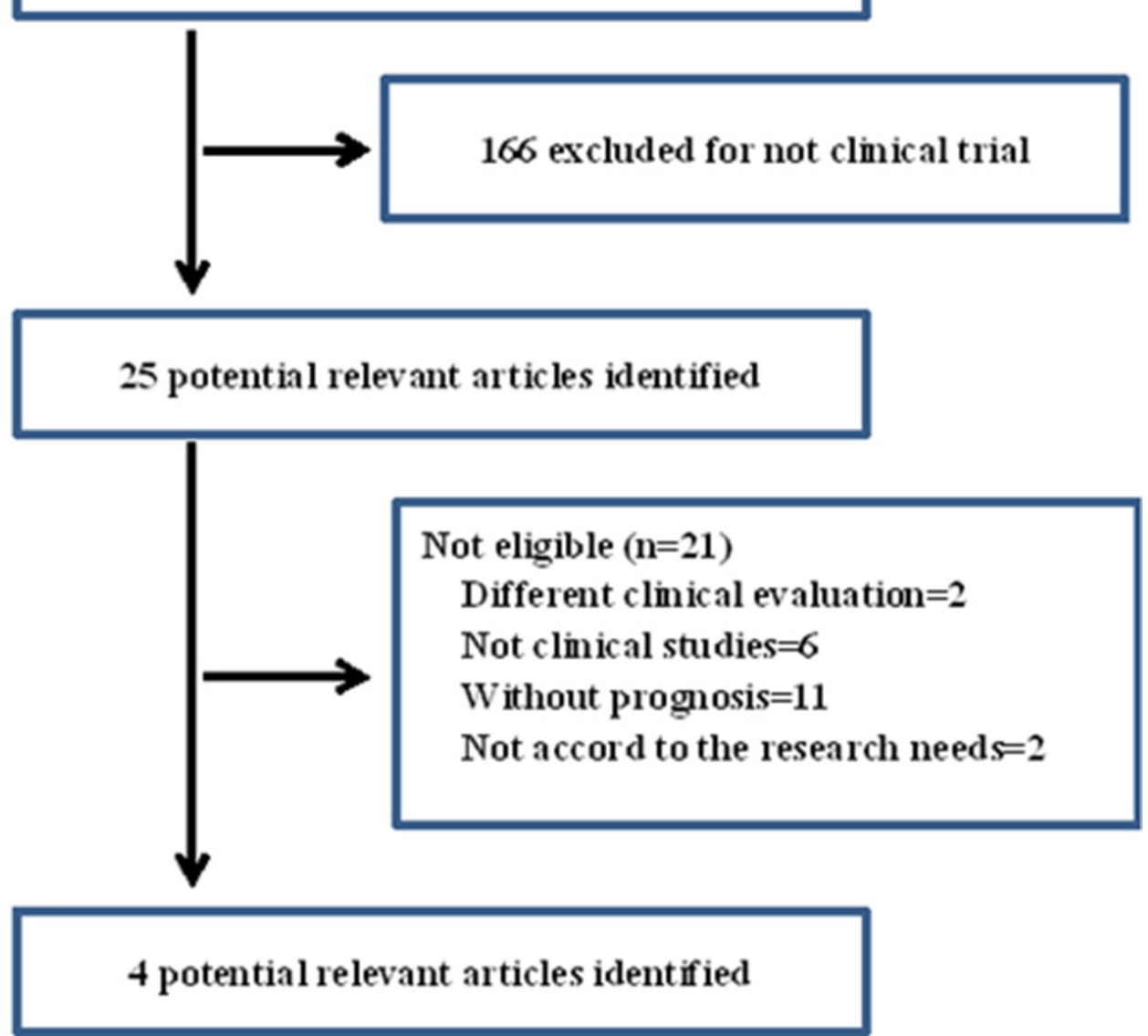

Figure 3: Flow diagram showing the number of citations identified, retrieved, extracted, and included in the final analysis. 
funnel plots and Begg's, trim-and-fill, and Egger's tests [11]. The reporting of the meta-analysis was performed in compliance with the PRISMA Statement. Four previously reported clinical trials $[6,10,12,13]$ and the results of the present study were included in the meta-analysis. A value of $P<0.05$ was considered statistically significant.

\section{Author contributions}

YQ Liu and YD Chen designed the research; TW Han and M Gao performed the experiments and analyzed the data; YQ Liu and YD Chen wrote the manuscript; JW Wang, SS Zhou and F Liu collected the data and revised the article. All authors reviewed the manuscript.

\section{ACKNOWLEDGMENTS}

We thank Hugh McGonigle, from Liwen Bianji, Edanz Group China (www.liwenbianji.cn/ac), for editing the English text of a draft of this manuscript.

\section{CONFLICTS OF INTEREST}

None.

\section{REFERENCES}

1. Chen W, Gao R, Liu L, Zhu M, Wang W, Wang Y, Wu Z, Li H, Zheng Z, Jiang L, Hu S. China cardiovascular disease report 2014. Chinese Circulation Journal (Chinese). 2015; 30:617-622.

2. Ueshima H, Sekikawa A, Miura K, Turin TC, Takashima N, Kita Y, Watanabe M, Kadota A, Okuda N, Kadowaki T, Nakamura Y, Okamura T. Cardiovascular disease and risk factors in Asia: a selected review. Circulation. 2008; 118:2702-9.

3. Sailam V, Karalis DG, Agarwal A, Alani F, Galardi S, Covalesky V, Athanassious C. Prevalence of emerging cardiovascular risk factors in younger individuals with a family history of premature coronary heart disease and low Framingham risk score. Clin Cardiol. 2008; 31:542-5.

4. Veeranna V, Zalawadiya SK, Niraj A, Pradhan J, Ference B, Burack RC, Jacob S, Afonso L. Homocysteine and reclassification of cardiovascular disease risk. J Am Coll Cardiol. 2011; 58:1025-33.

5. Chen YL, Bhasin A, YoussefAA, Wu CJ, Yang CH, Hsieh YK, Fang CY, Hang CL, Yip HK. Prognostic factors and outcomes in young chinese patients with acute myocardial infarction undergoing primary coronary angioplasty. Int Heart J. 2009; 50:1-11.

6. Rallidis LS, Sakadakis EA, Tympas K, Varounis C, Zolindaki M, Dagres N, Lekakis J. The impact of smoking on long-term outcome of patients with premature $(\leq 35$ years) ST-segment elevation acute myocardial infarction. Am Heart J. 2015; 169:356-62.
7. Barbash GI, White HD, Modan M, Diaz R, Hampton JR, Heikkila J, Kristinsson A, Moulopoulos S, Paolasso EA, Van der Werf T. Significance of smoking in patients receiving thrombolytic therapy for acute myocardial infarction. Experience gleaned from the International Tissue Plasminogen Activator/Streptokinase Mortality Trial. Circulation. 1993; 87:53-8.

8. Zahger D, Cercek B, Cannon CP, Jordan M, Davis V, Braunwald E, Shah PK. How do smokers differ from nonsmokers in their response to thrombolysis? (The TIMI4 trial.) Am J Cardiol. 1995; 75:232-6.

9. Ishihara M, Sato H, Tateishi H, Kawagoe T, Shimatani Y, Kurisu S, Sakai K, Ueda K. Clinical implications of cigarette smoking in acute myocardial infarction: Acute angiographic findings and long-term prognosis. Am Heart J. 1997; 134:955-60.

10. Chen KY, Rha SW, Li YJ, Jin Z, Minami Y, Park JY, Poddar KL, Ramasamy S, Wang L, Li GP, Choi CU, Oh DJ, Jeong $\mathrm{MH}$, and Korea Acute Myocardial Infarction Registry Investigators. 'Smoker's paradox' in young patients with acute myocardial infarction. Clin Exp Pharmacol Physiol. 2012; 39:630-5.

11. Shah PK, Forrester JS. Pathophysiology of acute coronary syndromes. Am J Cardiol. 1991; 68:16C-23C.

12. Qian G, Zhou Y, Liu HB, Chen YD. Clinical Profile and Long-Term Prognostic Factors of a Young Chinese Han Population ( $\leq 40$ Years) Having ST-Segment Elevation Myocardial Infarction. Acta Cardiol Sin. 2015; 31:390-7.

13. Rallidis LS, Lekakis J, Panagiotakos D, Fountoulaki K, Komporozos C, Apostolou T, Rizos I, Kremastinos DT. Long-term prognostic factors of young patients $(<\mathrm{or}=35$ years) having acute myocardial infarction: the detrimental role of continuation of smoking. Eur J Cardiovasc Prev Rehabil. 2008; 15:567-71.

14. Lietz M, Berges A, Lebrun S, Meurrens K, Steffen Y, Stolle K, Schueller J, Boue S, Vuillaume G, Vanscheeuwijck P, Moehring M, Schlage W, De Leon H, et al. Cigarettesmoke-induced atherogenic lipid profiles in plasma and vascular tissue of apolipoprotein E-deficient mice are attenuated by smoking cessation. Atherosclerosis. 2013; 229:86-93.

15. Zou N, Hong J, Dai QY. Passive cigarette smoking induces inflammatory injury in human arterial walls. Chin Med J (Engl). 2009; 122:444-8.

16. Otsuka R, Watanabe $\mathrm{H}$, Hirata $\mathrm{K}$, Tokai $\mathrm{K}$, Muro $\mathrm{T}$, Yoshiyama M, Takeuchi K, Yoshikawa J. Acute effects of passive smoking on the coronary circulation in healthy young adults. JAMA. 2001; 286:436-41.

17. Meliga E, De Benedictis M, Gagnor A, Belli R, Scrocca I, Lombardi P, Conrotto F, Aranzulla T, Varbella F, Conte MR. Long-term outcomes of percutaneous coronary interventions with stent implantation in patients $\leq 40$ years old. Am J Cardiol. 2012; 109:1717-21. 
18. Cole JH, Miller JI 3rd, Sperling LS, Weintraub WS. Longterm follow-up of coronary artery disease presenting in young adults. J Am Coll Cardiol. 2003; 41:521-28.

19. Weisz G, Cox DA, Garcia E, Tcheng JE, Griffin JJ, Guagliumi G, Stuckey TD, Rutherford BD, Mehran R, Aymong E, Lansky A, Grines CL, Stone GW. Impact of smoking status on outcomes of primary coronary intervention for acute myocardial infarction: The smoker's paradox revisited. Am Heart J. 2005; 150:358-64.

20. Andrikopoulos GK, Richter DJ, Dilaveris PE, Pipilis A, Zaharoulis A, Gialafos JE, Toutouzas PK, Chimonas ET. In-hospital mortality of habitual cigarette smokers after acute myocardial infarction: The 'smoker's paradox' in a countrywide study. Eur Heart J. 2001; 22: 776-84.

21. Ruiz-Bailén M, de Hoyos EA, Reina-Toral A, Torres-Ruiz JM, Alvarez-Bueno M, Gómez Jiménez FJ, and ARIAM Group. Paradoxical effect of smoking in the Spanish population with acute myocardial infarction or unstable angina: results of the ARIAM Register. Chest. 2004; 125:831-40.

22. Park KW, Park JJ, Jeon KH, Kang SH, Oh IY, Yang HM, Cho HJ, Lee HY, Kang HJ, Koo BK, Oh BH, Park YB, Kim HS. Enhanced clopidogrel responsiveness in smokers: Smokers' paradox is dependent on cytochrome P450 CYP1A2 status. Arterioscler Thromb Vasc Biol. 2011; $31: 665-71$.
23. Berger JS, Bhatt DL, Steinhubl SR, Shao M, Steg PG, Montalescot G, Hacke W, Fox KA, Lincoff AM, Topol EJ, Berger PB; CHARISMA Investigators. Smoking, clopidogrel, and mortality in patients with established cardiovascular disease. Circulation. 2009; 120:2337-44.

24. Wang Y, Wang Y, Zhao X, Liu L, Wang D, Wang C, Wang C, Li H, Meng X, Cui L, Jia J, Dong Q, Xu A, et al, and CHANCE Investigators. Clopidogrel with aspirin in acute minor stroke or transient ischemic attack. N Engl J Med. 2013; 369:11-19.

25. Bliden KP, Dichiara J, Lawal L, Singla A, Antonino MJ, Baker BA, Bailey WL, Tantry US, Gurbel PA. The association of cigarette smoking with enhanced platelet inhibition by clopidogrel. J Am Coll Cardiol. 2008; 52:531533.

26. Ovbiagele B, Wang J, Johnston SC, Wang A, Wang D, Wang Y, Zhao X, Wang Y. Effect of Clopidogrel by Smoking Status on Secondary Stroke Prevention. Circulation. 2017; 135:315-316. 